\title{
EDWARD BECK'S TREATISE ON \\ LEPRA VULGARIS (1834)
}

BY

ARTHUR ROOK, M.D.

Cambridge

This account of a forgotten contributor to the literature of dermatology arose out of the chance discovery in the Cambridge University Library of a short tract, which proved to be exceedingly rare. 'A Practical Treatise on Lepra Vulgaris', by Edward Beck, M.D., was published in Ipswich in 1834. It is probable that few copies have survived, as this work is not possessed by the Libraries of the Royal Colleges or by the Royal Society of Medicine. There are copies in the British Museum and in the National Medical Library in Washington.

Edward Beck was born in Needham Market, Suffolk, on I I July I 794, the eldest surviving son of Edward Bigsby Beck, surgeon. He was baptized in the neighbouring village of Barking two days later. His mother was Dorothy Anne, daughter of the Reverend Thomas Bateman, Rector of Igburgh with Langford, Norfolk. The family of Beck, coming originally from Lincolnshire, was well known in Suffolk in the eighteenth and nineteenth centuries, and many of Edward Beck's relatives were medical practitioners, clergymen or small landowners, mainly in the Ipswich area. His paternal grandfather was Edward Beck, surgeon, of Coddenham and Needham Market (died 1780 at the age of forty-eight). Two of his brothers entered the medical profession, Francis Diggon Beck, surgeon of Claydon, and Thomas Bateman Beck, surgeon of Needham Market (Davy MSS.).

Edward Beck attended school at Dedham, Essex. In 1812 he entered St. Thomas's Hospital as a Surgeon's Pupil, paying a fee of 24 guineas for this privilege, and becoming M.R.c.s. in 1813. He was admitted Fellow Commoner of Jesus College, Cambridge, on 4 October I8I9. He acquired the degree of M.B. in 1825 and proceeded to the M.D. in 1832 .

Until 1813 the requirements for membership of the Royal College of Surgeons were far from exacting. Candidates must have served an apprenticeship to a member and must have been approved by the Court of Examiners. No attendance at lectures or other formal teaching was demanded, and the examination, which was oral and lasted between one and two hours, included no practical test. In 1813 attendance at a course of lectures in anatomy and on the surgical practice of a hospital for six 


\section{Edward Beck on Lepra Vulgaris}

months became compulsory. At St. Thomas's Hospital in 1812 Beck would have attended the lectures of Sir Astley Cooper in anatomy and physiology (Parsons, 1936). He had probably entered on his apprenticeship in 1810, when he was sixteen. He may have been apprenticed to his father in Needham Market or, as he subsequently practised in that town, to a practitioner in Ipswich.

In 1819 the Cambridge Medical School was still slumbering and the period of its great awakening and expansion lay half a century in the future. Winstanley (1935) compares the official requirements, which appear adequate, with the complacent remarks of the editor of the University Calendar for 1802 . 'A student of medicine in this University is not required', he wrote, 'to attend any lectures, but is left to acquire his knowledge from such sources as his own discretion may point out.' Many students failed to fulfil even the residential requirements. The examination papers for the M.B. degree in June 1828 show a respect for tradition which was in keeping with the spirit of the times, but indicate that, although the University provided virtually no teaching, the candidate was expected to have acquired some knowledge of his subject. The first paper contained eleven questions mainly on anatomy. The second paper, of fourteen questions, covered medicine, pathology and materia medica. Among the questions in 1828 were: 'What remedy does Sydenham recommend in diarrhoea supervening on gout?' 'In what class and order of Cullen's nosology is dyspepsia placed??

It is interesting to speculate on the source of his interest in dermatology. It is unlikely that the staff of St. Thomas's Hospital stimulated him in this direction. John Elliotson (Tubbs, 1953) was almost contemporary with Beck as a student at the Borough Hospitals (St. Thomas's and Guy's). He later wrote (1829-30): 'When I was a student in London there was no information given in the lectures on diseases of the skin except the exanthemata.' Beck may have attended the public dispensary in Carey Street, where Bateman carried on Willan's teaching on skin diseases. This was a general and not a dermatological dispensary, but Willan's fame and known interest in dermatology probably attracted an increasing proportion of sufferers from skin diseases. In his tract Beck does not mention attendance at Bateman's clinics.

Edward Beck was in practice in Ipswich on his own account by 1824 . He was presumably engaged largely in general practice in his earlier years, although his degree of M.D. would give him additional status and he was no doubt occasionally called in consultation by his colleagues. Later he may have been able to confine his practice to that of a physician. He certainly achieved considerable professional and worldly success. He was appointed Physician to the East Suffolk and Ipswich Hospital when it was 
established in $18{ }_{3} 6$. According to a contemporary newspaper he was, by the year 1847 , a magistrate of the borough, enjoyed a very lucrative practice and possessed property to the amount of $£ 40,000$.

In 1819 he had married Sarah Elizabeth Walter of Debenham. Their only child was born in Cambridge the following year and died when only eight months old. Further misfortunes overtook Edward Beck in I847, when heavy losses in railway speculations compelled his sudden departure for the Continent, leaving liabilities to the amount of $£ 25,000$. His lack of judgement in financial matters evidently did not lessen the esteem in which he was held by his professional colleagues for he was elected President of the Suffolk Medical Book Society in 1852-53 and again in 1860-61. This Society, like so many others in England, was originally founded, as its name implies, solely to facilitate the exchange of medical books, but soon evolved into a medical society in the modern sense. Beck died on ro October 1862 at his residence in Northgate Street, Ipswich. His death was reported in the British Medical Fournal, the Lancet and the Medical Times and Gazette, but he was not considered worthy of an obituary notice.

The 'Practical Treatise', which was apparently Beck's only published work, appeared in 1834 , and it is possible that it was based on the thesis submitted for his M.D. degree two years earlier. Unfortunately the theses of that period have not been retained by the University Library. The full title was 'A Practical Treatise on Lepra Vulgaris with cases that have Uniformly yielded to the plan of treatment laid down, to which are added Observations and the Treatment of Some of the local varieties of Psoriasis, with cases. By Edward Beck, M.D.'. The slim volume consists of 74 pages, octavo; the copy in the University Library is bound together with other contemporary medical tracts and is without its original binding.

Before considering Beck's views on psoriasis and its treatment it may be useful to summarize the contemporary ideas on this condition, as in the Treatise, as Beck points out somewhat apologetically in his preface, 'some remarks are hazarded at variance with opinions of those authors, who have before written on Lepra'.

During the first half of the nineteenth century dermatology was striving to acquire a generally acceptable and uniform system of nomenclature and reliable criteria of morphological diagnosis. Willan's great contribution ( 1808 ) was the first comprehensive attempt to provide a logical classification based on such criteria. His work gradually gained wide acceptance, but other systems of classification had their supporters. Alibert's system, in particular, exerted considerable influence. The confused state of dermatological thought in Beck's student days is well illustrated by the following passage from the writings of Wilkinson (1822), a rival of Bateman and a critical admirer of Bateman's master, Willan: 
A

\title{
PRACTICAL TREATISE
}

os

\section{LEPRA VULGARIS,}

\author{
WITH CASES
}

THAT HAVE

שNIFORMLY YIELDED TO THE PLAN OF TREATMENT LAID DOWN

TO พВIси ARE ADDED,

\section{OBSERVATIONS}

On the Treatment of

\section{SOME OF THE LOCAL VARIETIES}

o1

\section{PSORIA S I S,}

WITH CASES.

\section{BY EDWARD BECK, M. D.}

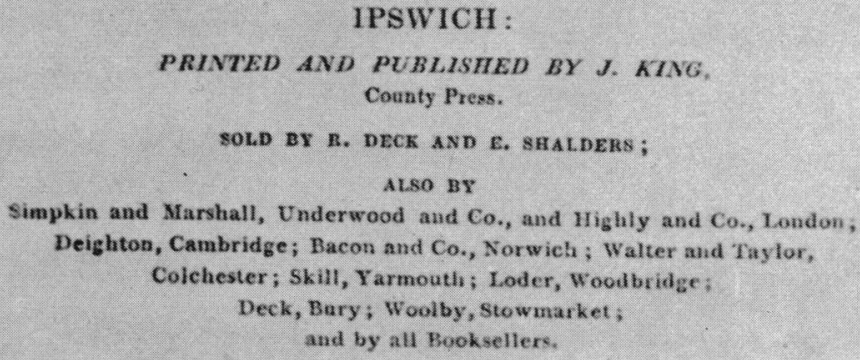

Title page of Edward Beck's

Treatise on Lepra Vulgaris, I 834 


\section{Edward Beck on Lepra Vulgaris}

From the perusal of Monsieur Alibert's inflated fustian in his 'Description des Maladies de la Peau' I rise, as I think every sober man must rise, puzzled and disgusted $;.$. he has continued ... to render this department of the science more confused and incomprehensible than he found it.

Before Willan the terms psora, psoriasis, lepra and alphos had been applied according to the whim of the writer, to a variety of conditions, many of which are now difficult to identify precisely. Hebra (1868) points out that Celsus described two conditions which appear to be psoriasis, one he calls alphos and the other a species of impetigo. There was no more accurate definition of psoriasis than that of Celsus in any work of the thirteenth to the eighteenth centuries. Lorry and Plenck in the eighteenth century used the word lepra for any skin condition of loathsome appearance.

Willan gave a good description of psoriasis, but called it lepra graecorum, and attempted to distinguish a different condition under the term psora leprosa or psoriasis. Many writers soon questioned the validity of this distinction. Wilkinson ( 1822 ), in many incidental references to lepra and psoriasis, does not suggest that they are identical, but Plumbe (1824) wrote: 'I am fully convinced that all the purposes of useful discussion would have been effectually consulted by including these under one head'; for which he wished to retain the term lepra. No general agreement was reached for sixty years or more. McCall Anderson in 1865 wrote: 'Lepra on the other hand, which has long been and by some authors still is, separated from Psoriasis, has no right to be considered in the light of a separate affection.' Erasmus Wilson (1867) still thought otherwise and also wished to restore the term alphos. Wilson and other participants in this terminological controversy are discussed by Meenan (1955), and Russell (1950) provides an interesting account of its origins.

It is not surprising that discussions on the cause of psoriasis should have lacked any factual basis, but they were already pursued with vigour. The numerical approach to the study of possible aetiological factors was not widely adopted until quite late in the century and, in the absence of even this often ineffectual check, speculation was still wilder than it is today. The influence of heredity, climate, the emotions and various constitutional states was disputed then as now, and many curious deductions from unsound clinical observations found some favour. Gaskoin (1875), for example, stated: 'The practice of tubbing, which is now in daily use has sent us a good many cases.'

Treatment was disconcertingly similar to that of today. The local application of tar had been advocated by Willan and Bateman. Wilkinson used tar freely. Plumbe recommended tar, tar and sulphur, and sulphur vapour baths ('at Mr. Green's establishment in Bury Street'). He also used 


\section{Arthur Rook}

ointment of calomel and of white and red precipitate of mercury. Bleeding, which the teaching of Broussais made the universal remedy during the first half of the century, naturally found its advocates in a disease as intractable as psoriasis. As late as 1875 Gaskoin warned against excessive and repeated bleedings, but still considered bleeding useful in exceptional cases. 'As to local bleeding I do not recommend it or employ it though this method has been largely used in London practice in the preceding generation.'

Arsenic had been sold as a popular remedy as 'tasteless ague drops' or 'Edward's ague tincture' during the eighteenth century and possibly earlier (Behcet, I93I). Fowler had these drops analysed and greatly extended their use in the treatment of malaria. Various preparations of arsenic were used with the support of Withering, Haygarth, Pearson and other prominent physicians, in a variety of diseases. Girdlestone ( $\left.1785^{-1822}\right)$, who practised for thirty years at Great Yarmouth, mentioned (1806) that arsenic was misused for ague 'in the hands of the lower orders', and stated that he had used it successfully in lepra, several years previously. Willan and Bateman did not use arsenic much, but by 1830 most British writers on skin diseases were strongly recommending its use in large doses in long and repeated courses, and the leading authorities (Anderson, Tilbury Fox, Liveing, McCall Anderson) forty years later were apparently unaware of its dangers. Gaskoin (1875) found that symptoms such as colic and diarrhoea, redness of the conjunctiva and tingling of the extremities were frequent, and considered them 'indications of much value rather than an occasion of alarm'.

\section{Beck's treatise}

Against this background of contemporary views on psoriasis we can consider Beck's treatise. In his preface, pages $i$ to viii, he modestly disclaims 'any expectation of throwing any additional light on the history of the disease'. His treatise 'is put forth ... f from a desire to lay before the profession a plan of treatment, which I have found to be uniformly successful, in order that its efficacy may be submitted to the most extensive trial'. He continues (page v):

The remedies most confidently recommended by Willan, Bateman and others, have repeatedly disappointed my expectations, and, I am strongly inclined to believe, the expectations also of the profession generally. Arsenic, one of the most lauded, is hardly more valuable than the rest, for it must be pushed to a considerable extent before any impression is made on the disease, and then its injurious effects on the system are such that a steady perseverance in its use, for any length of time, is in most cases entirely out of the question.

The next five pages are devoted to a description of 'lepra' (psoriasis), which is undistinguished and is certainly inferior to Plumbe's interesting I64 


\section{Edward Beck on Lepra Vulgaris}

and detailed account. However, Beck deserves credit for recognizing that despite its customary intractable course it may clear spontaneously, 'having an evident tendency to improvement, and, with little aid from medicine, in two or three weeks is entirely removed'.

Beck admitted that 'lepra' was occasionally hereditary, but believed that such cases were uncommon. He considered that vaccination was a frequent cause in the predisposed, but was 'unwilling to add to the extraordinary prejudice entertained against vaccination'. He agreed with Willan that 'A cold and moist state of the atmosphere manifestly protracts the cure; and exposure to cold and wet will bring on recurrences of the disease, especially in spring and autumn.' 'Anxiety of mind has a marked effect on lepra, aggravating the local irritation very speedily. Errors of diet will produce the same effect, and sometimes will bring on an attack of the disease.'

The 'specific plan' of treatment consisted in the external application and oral administration of tar. Sulphur and Pix liquida in Adeps praeparata was to be applied, and Pix liquida and Flora tritici to be given in the form of pills three times daily. Acute and extensive cases required a 'preparatory plan' in which lead notions and other bland applications were recommended. The great importance of strict attention to detail is emphasized.

On pages $34-56$ the reports of six cases are fairly fully presented. It is doubtful whether cases I and 2 would now be accepted as psoriasis; both appear to be varieties of chronic eczema. The remaining four cases are good examples of various clinical manifestations of psoriasis.

The last fifteen pages of the treatise are devoted to what Beck called 'Psoriasis or scaly tetter' and which he wished to differentiate from lepra. Some of his cases we should now call psoriasis and others were seborrhoeic dermatitis or chronic eczema. The three cases reported are all examples of eczema. Beck treated these cases with mild aperients and frequent applications of a decoction of bran during the hot and irritable stage; after a few days he gave camphor oz. $\frac{1}{2}$ with cerat. cetac oz. I and later a powder containing sodium carbonate and sulphur.

Two British and two German journals published notices of Beck's book. Copies of the latter (Allgem. Repertor. der med.-chir. Fournalistik des Auslandes, 1834, and Allgem. med. Zeitung, 1835) could not be obtained. Both the Medico-Chirurgical Review and the Lancet printed extended reviews, which mostly amount to such detailed summaries of the contents of the little book that its purchase is rendered superfluous; such was the contemporary practice. The writer in the Medico-Chirurgical Reviewe finds himself with 'no space left for comments, which we leave to the fancy, the judgement or experience of our readers'. 


\section{Arthur Rook}

The Lancet, in small matters as in great, never refrained from pertinent and often witty comment:

The volume forms such a contribution to medical science as a conscientious practitioner should make; but since books are now-a-days so difficult of dissemination, we wonder the author did not present his paper to one of the medical journals, ten of our own pages would embrace the seventy-four of the Doctor.

The desideratum (a successful remedy) is promised by Dr. Beck, and then supplied in the foregoing volume, which, as emblems and mottoes are selected from every source, might, not inappropriately, as healing is a sacred art, have had its title page graced by a Noah's ark, and these words-'Thou shalt pitch it within and without with pitch'.

No great importance in the history of dermatology can be claimed for Beck's modest contribution. His 'special plan' of treatment, the principal thesis of his book, was no better but certainly no worse than many that have followed it. No doubt the early successes Beck achieved were largely due to his personal enthusiasm and he will certainly later have been disillusioned. He deserves some credit for his appreciation of the risks of arsenic and its questionable efficacy when his contemporaries and many of his successors were loud in its praise and oblivious of its dangers. His aetiological speculations seem to us more restrained and less extravagant than those of many whose fame has endured.

\section{ACKNOWLEDGEMENTS}

I would like to express my thanks to the many people who have helped me rescue Beck from oblivion; the librarians of the Royal Society of Medicine and of the Royal College of Surgeons, and the Assistant Librarian of the Royal College of Physicians; the deputy County Archivist of East Suffolk; the Chief Librarian of Ipswich County Library; Mr. H. R. Lingwood of Woodbridge; the Secretary, Ipswich Group Hospital Management Committee; Mr. G. A. R. Winston of the Wills Library, Guy's Hospital; Mr. W. J. Bishop.

\section{REFERENCES}

Benget, P. E. (1931). 'The History of the Use of Arsenic in Dermatology.' Arch. Derm. Syph. (Chicago), xxiII, I 10.

Davy, D. E. (1948). Athenae Suffolcienses, Vol. Iv, f. I5 (ADD. MS. 19, I68, f. I5 British Museum); Pedigree of the Beck family of Worlingworth, Coddenham and Needham Market (ADD. MS. 19, I 7 British Museum).

Fox, TIL B URY (1864). Skin Diseases. London.

Gask OIN, Ge orge (1875). On the Psoriasis or Lepra. London.

He B RA, F. (1868). On Diseases of the Skin, Vol. Ir. London, New Sydenham Society.

Liveing, R. (1887). A Handbook on Diseases of the Skin. $5^{\text {th }}$ ed. London. 


\section{Edward Beck on Lepra Vulgaris}

MaGall Anderson, T. (1865). On Psoriasis and Lepra. London.

Meenan, F. O. G. (I955). 'A Note on the History of Psoriasis.' Irish 7. med. Sci., p. I4I. Parsons, F. G. (1936). The History of St. Thomas's Hospital, Vol. III. London, Methuen.

Plumbe, S. (1824). A Practical Treatise on Diseases of the Skin. London.

Russell, B. (1950). 'Lepra, Psoriasis, or the Willan-Plumbe Syndrome.' Brit. 7. Derm., LXII, $35^{8}$.

Tuв Bs, F. A. (1953). 'John Elliotson at St. Thomas's Hospital.' St. Thos. Hosp. Gaz., LI, 47.

Wilkinson, J. H. (1822). Remarks on Cutaneous Diseases. London.

Wilson, ERAsmus (1867). On Diseases of the Skin. 6th ed. London.

Winst anley, D. A. (1935). Unreformed Cambridge. Cambridge University Press. p. 60.

UNSIGNED REVIEW (1834). Lancet, II, 909.

Unsigned Review (1834). Med. Chir. Rev., xxi, 495 . 